\title{
Contrast Dependence and Differential Contributions from Somatostatin- and Parvalbumin-Expressing Neurons to Spatial Integration in Mouse V1
}

\author{
Hendrikje Nienborg, ${ }^{1,2}$ Andrea Hasenstaub, ${ }^{1}$ Ian Nauhaus, ${ }^{1}$ Hiroki Taniguchi, ${ }^{3}$ Z. Josh Huang, ${ }^{3}$ and \\ Edward M. Callaway ${ }^{1}$ \\ ${ }^{1}$ Salk Institute for Biological Studies, La Jolla, California 92037, ${ }^{2}$ Werner Reichhardt Centre for Integrative Neuroscience, University of Tuebingen, 72076 \\ Tuebingen, Germany, and ${ }^{3}$ Cold Spring Harbor Laboratory, Cold Spring Harbor, New York 11724
}

\begin{abstract}
A characteristic feature in the primary visual cortex is that visual responses are suppressed as a stimulus extends beyond the classical receptive field. Here, we examined the role of inhibitory neurons expressing somatostatin $\left(\mathrm{SOM}^{+}\right)$or parvalbumin $\left(\mathrm{PV}^{+}\right)$on surround suppression and preferred receptive field size. We recorded multichannel extracellular activity in V1 of transgenic mice expressing channelrhodopsin in $\mathrm{SOM}^{+}$neurons or $\mathrm{PV}^{+}$neurons. Preferred size and surround suppression were measured using drifting squarewave gratings of varying radii and at two contrasts. Consistent with findings in primates, we found that the preferred size was larger for lower contrasts across all cortical depths, whereas the suppression index (SI) showed a trend to decrease with contrast. We then examined the effect of these metrics on units that were suppressed by photoactivation of either $\mathrm{SOM}^{+}$or $\mathrm{PV}^{+}$neurons. When activating $\mathrm{SOM}^{+}$ neurons, we found a significant increase in SI at cortical depths $>400 \mu \mathrm{m}$, whereas activating $\mathrm{PV}^{+}$neurons caused a trend toward lower SIs regardless of cortical depth. Conversely, activating $\mathrm{PV}^{+}$neurons significantly increased preferred size across all cortical depths, similar to lowering contrast, whereas activating $\mathrm{SOM}^{+}$neurons had no systematic effect on preferred size across all depths. These data suggest that $\mathrm{SOM}^{+}$and $\mathrm{PV}^{+}$neurons contribute differently to spatial integration. Our findings are compatible with the notion that $\mathrm{SOM}^{+}$neurons mediate surround suppression, particularly in deeper cortex, whereas $\mathrm{PV}^{+}$activation decreases the drive of the input to cortex and therefore resembles the effects on spatial integration of lowering contrast.
\end{abstract}

\section{Introduction}

Surround suppression, the inhibitory influence of visual stimuli extending beyond a neuron's classical receptive field, is characteristic of many neurons in the primary visual cortex (Hubel and Wiesel, 1968; Blakemore and Tobin, 1972; Allman et al., 1985; DeAngelis et al., 1994; Levitt and Lund, 1997; Angelucci et al., 2002a; Cavanaugh et al., 2002). The phenomenon provides an easily quantifiable example of how neurons in early visual cortex are influenced by contextual information from beyond their receptive field. It has received substantial attention because such mechanisms are thought to contribute to perceptual phenomena such as figure-ground segmentation or contour integration

Received Nov. 9, 2012; revised April 24, 2013; accepted May 24, 2013.

Author contributions: H.N. and E.M.C. designed research; H.N. performed research; A.H., I.N., H.T., and Z.J.H. contributed unpublished reagents/analytic tools; H.N. analyzed data; H.N. and E.M.C. wrote the paper.

This work was supported by the Gatsby Charitable Foundation (E.M.C.), the Kavli Institute for Brain and Mind Innovative Research Grant (H.N. and E.M.C.), the National Institutes of Health (Grant \#EY020569 to H.N., Grant \#EY010742 and Grant \#EY022577 to E.M.C., and Grant \#EY019821 to I.N.), and a Starting Independent Researcher grant (H.N.) from the European Research Council (project acronym: NEUROOPTOGEN). We thank Vincent Bonin and Mark Histed for helpful comments on an earlier draft of this manuscript.

The authors declare no competing financial interests.

Correspondence should be sent to Edward M. Callaway, Salk Institute for Biological Studies, 10010 N. Torrey Pines Road, La Jolla, CA 92037. E-mail: callaway@salk.edu.

A. Hasenstaub's present address: UCSF School of Medicine, Department of Otolaryngology, 675 Nelson Rising Lane, San Francisco, CA 94158.

DOI:10.1523/JNEUROSCI.5320-12.2013

Copyright $\odot 2013$ the authors $\quad 0270-6474 / 13 / 3311145-10 \$ 15.00 / 0$
(Dobbins et al., 1987; Lamme, 1995; Zipser et al., 1996). First studied extensively in the macaque monkey (Hubel and Wiesel, 1968; Sceniak et al., 1999; Angelucci et al., 2002a, 2002b; Cavanaugh et al., 2002; Bair et al., 2003; Angelucci and Bressloff, 2006; Ichida et al., 2007) and cat (DeAngelis et al., 1994), it has recently also been observed in mouse V1 (Van den Bergh et al., 2010; Adesnik et al., 2012).

A commonly used way to quantify the spatial structure and the interactions between the excitatory center of the receptive field and the inhibitory influences of the surround is to measure size tuning curves, the responses to circular stimuli of increasing radius (DeAngelis et al., 1994; Levitt and Lund, 1997; Sceniak et al., 1999; Cavanaugh et al., 2002). Using this paradigm, a neuron's preferred size is defined as the radius for which the neuron responds maximally (if it shows surround suppression) or the minimal radius for which its response asymptotes (in the absence of surround suppression). In monkey V1, it has been shown that when lowering the contrast of a stimulus, a neuron's preferred size increases (Kapadia et al., 1999; Sceniak et al., 1999); however, it is unclear whether the same is true in mouse V1. In this study, we therefore first examined whether size tuning was contrast dependent in the mouse. Experimental and theoretical work has suggested that several mechanisms contribute to surround suppression in cortex. Because surround suppression is present in the retina and the thalamus, it is likely at least partially inherited from subcortical processing. Other findings, such as the relative 
weakness (Kremers et al., 2001; Solomon et al., 2002; Bonin et al., 2005) or absence of contrast dependence of size tuning in the thalamus (Sceniak et al., 2006), suggest that cortical processing is also important. Recurrent horizontal connections or feedback from extrastriate cortex acting via local inhibitory neurons have been proposed, supported by anatomical data and physiological findings on the temporal and spatial properties of the effects (Bair et al., 2003; for review, see Angelucci and Bressloff, 2006). Studies manipulating GABAergic transmission pharmacologically have reported mixed effects of inhibition on size tuning (Sillito and Versiani, 1977; Bolz and Gilbert, 1986; Ozeki et al., 2004). Optogenetic approaches available in the mouse model have opened up the possibility of examining the role of specific cortical circuit elements. For example, Adesnik et al. (2012) recently implicated somatostatin-expressing $\left(\mathrm{SOM}^{+}\right)$neurons in surround suppression by showing that $\mathrm{SOM}^{+}$interneurons in mouse V1 lack surround suppression and that their inactivation reduces surround suppression of pyramidal neurons in layer II/III. We build on these findings here by using selective activation of $\mathrm{SOM}^{+}$or parvalbumin-expressing $\left(\mathrm{PV}^{+}\right)$cells, investigating contrast dependence, and recording at different cortical depths.

\section{Materials and Methods}

\section{Animals}

All procedures were performed in accordance with the guidelines of the National Institutes of Health and were approved by the institutional animal care and use committee at the Salk Institute. Mice used were 7- to 14-week-old Ai27 Rosa-CAG-LSL-hChR2H(134R)-tdTomato-WPRE mice (JAX stock \#012567; The Jackson Laboratory, donated by Hongkui Zeng, Allen Institute for Brain Science; Madisen et al., 2012) crossed with PV-Cre mice (JAX stock \#008069; The Jackson Laboratory, donated by Silvia Arber, Friedrich Miescher Institute; Hippenmeyer et al., 2005) or with SOM-IRES-Cre mice (JAX stock \#013044; The Jackson Laboratory, donated by Z. Josh Huang, Cold Spring Harbor Laboratory; Taniguchi et al., 2011). Expression of ChR2 in $\mathrm{SOM}^{+}$or $\mathrm{PV}^{+}$neurons was confirmed by genotyping. Eleven (five female) $\mathrm{PV}^{+}$mice and eight (four female) $\mathrm{SOM}^{+}$mice were included in this study.

\section{Animal preparation and surgery}

A custom-made titanium frame was mounted to the skull using tissue adhesive (Vetbond; 3M) and dentistry grip cement (Caulk DENTSPLY) under general isofluorane anesthesia ( $2 \%$ during induction of anesthesia, $1 \%-1.8 \%$ during surgery), usually at least $1 \mathrm{~d}$ before the recording session. After induction of isofluorane anesthesia, the mouse was positioned on a heating pad and $\sim 0.1 \mathrm{ml}$ of an injectable local anesthetic $(2 \%$ lidocaine) was subcutaneously injected above the skull as an additional anesthetic before removing the skin. After implantation, the aperture of the frame and the wound margin were covered with Kwik Cast silicone elastomer (World Precision Instruments). Ibuprofen $(30 \mathrm{mg} / \mathrm{kg}$ ) was given postoperatively. On the day of recording, a craniotomy $(\sim 2 \mathrm{~mm}$ in diameter, centered at $3.5 \mathrm{~mm}$ posterior of bregma and $2.5 \mathrm{~mm}$ lateral from the midline) was performed under general anesthesia (isofluorane: $2 \%$ during induction and $1 \%-1.2 \%$ during surgery) supported by chlorprothixene $1.3 \mathrm{mg} / \mathrm{kg}$ intramuscularly. Atropine $(0.3 \mathrm{mg} / \mathrm{kg})$ and dexamethasone $(2 \mathrm{mg} / \mathrm{kg})$ were also injected subcutaneously to reduce edema and secretions. The exposed dura was then covered with a thin layer of saline in $2 \%$ type IIIA agarose (Sigma). To prevent drying, the eyes were covered with ophthalmic lubricant ointment and with a thin layer of silicone oil for recording. After craniotomy, the animals were transferred to a horizontal running wheel (Fast-Trac \#908-996-2155; Bio-Serv) and the head was fixed by clamping to the implanted frame. During recordings, the animals were taken off of the isofluorane anesthesia and no additional chlorprothixene was given if possible because of its longer half-life. Due to the light chlorprothixene sedation, the animals were usually quiescent, but occasional movements were registered and trials during which movement exceeded $0.5 \mathrm{~cm} / \mathrm{s}$ were removed from analysis.

\section{Electrophysiology}

NeuroNexus silicon probes (A1x32-Edge-5 mm-20-177, A1x32-5 mm25-177 or A1x16-3 mm50-177, or A2x16-10 mm-50-500-177) were used. For the one recording session in which a $2 \times 16$ probe was used, the data for the two shanks were recorded in separate experiments and the stimulus centered on the receptive fields for each shank separately. Electrodes were held by a Kopf stereotaxic arm mounted on a custom-made rail and always inserted orthogonally to the cortical surface such that the topmost contact was just below the dura and still clearly visible through the translucent dura. After positioning of the optical fiber and insertion of the recording electrode, additional saline in 3\% type IIIA agarose was added for stabilization. Visual stimulation experiments began after a settling period of $\sim 30$ min after electrode insertion into cortex. At the end of the recording session, the animals were killed with Euthasol (Virbac). Signals were recorded using a Tucker Davis Technology (TDT) System 3 recording system with a RZ2 multichannel workstation, sampled at $25 \mathrm{kHz}$, and band-pass filtered $(300 \mathrm{~Hz}-5 \mathrm{kHz}$ for unit recordings). Thresholds to trigger spiking events were usually set at $6 \mathrm{SDs}$ above the noise. Offline spike sorting was done by hand based on PCA using TDT OpenSorter. Clusters with typical spike waveforms were considered as multi-unit activity, and only well isolated units with a clear refractory period were classified as single units (SUs). For each channel, clusters were restricted to two single units and one multi-unit cluster maximally.

Visual stimuli

Visual stimuli were presented on a Dell $20.5^{\prime}$ by $11.5^{\prime}$ gamma-corrected monitor, $81 \mathrm{~cd} / \mathrm{m}^{2}$ mean luminance, positioned $10 \mathrm{~cm}$ in front of the animal, centered on the receptive field. Pupil size was not measured, but published data report that the pupil area in mice at such luminance is $<0.25 \mathrm{~mm}^{2}$ (Pennesi et al., 1998). Visual stimuli were generated on a Mac running MATLAB using the psychophysics toolbox (Brainard, 1997; Pelli, 1997; Kleiner et al., 2007). Preceding each size tuning experiment, the receptive field position was measured. To identify the receptive field profiles along a horizontal and vertical axis, respectively, a drifting grating visible only in an elongated rectangular aperture was presented at different horizontal or vertical positions, respectively. The aperture of the grating was $10^{\circ} \times 90^{\circ}$ (width by height) to measure the horizontal axis and $90^{\circ}$ wide and $10^{\circ}$ high to measure the vertical axis. The positions of the peaks of the horizontal and vertical receptive field profiles were then used as the centers of receptive field. For size-tuning experiments, vertically oriented circular square-wave gratings (spatial frequency $=0.015 \mathrm{cpd}$, temporal frequency $=0.67 \mathrm{~Hz}$, stimulus duration $1.5 \mathrm{~s}$, intertrial duration $3 \mathrm{~s}$ with uniform midgray screen, $100 \%$ contrast) of different radii (typically $1.8^{\circ}, 3.5^{\circ}, 6.9^{\circ}, 13.7^{\circ}, 27.3^{\circ}, 54.5^{\circ}$ ) were used, interleaved in pseudorandom order, with at least 10 repeats for each parameter combination. Size tuning at different contrasts and for optical stimulation was usually examined in separate experiments. To examine contrast dependence of size tuning, radius and contrast were changed (typically $30 \%$ and $100 \%$, range for the low contrast $13-35 \%$, median for the low contrast 30\%) between trials. Interleaved blank stimuli (uniform midgray screen) were included in all experiments.

\section{Optical stimulation}

Blue light (470 nm) was delivered with an optical fiber (2 mm diameter) coupled to an LED, the output power of which was regulated via a custom-made control by an analog signal generated by the TDT system. The optical fiber was positioned directly above the cortical surface at a distance of $\sim 100-200 \mu \mathrm{m}$ from the electrode. The light level was adjusted such that it reduced the visually driven activity in suppressed units to $\sim 50-60 \%$. This typically required light intensities of $0.5-2 \mathrm{~mW} / \mathrm{mm}^{2}$ at the surface of the brain. Trials with and without optical stimulation were interleaved during the size-tuning experiments. For trials with optical stimulation, the optical stimulation preceded the visual stimulus by $1 \mathrm{~s}$ and was kept on for $0.5 \mathrm{~s}$ after offset of the visual stimulus.

\section{Analysis}

All analyses used the mean responses (in spikes/s) to 1 cycle of the stimulus presentation ( $1.5 \mathrm{~s}$ ) above the baseline response (mean response in spikes/s to a $1.5 \mathrm{~s}$ presentation of the blank stimulus). For trials with light stimulation, the baseline response corresponded to the mean response to 
the blank stimulus during optical stimulation. Only those neurons for which activity to the grating stimulus significantly exceeded that to the blank stimulus were evaluated separately for each experimental condition (LED on/off, low contrast and high contrast). For the subset of experiments for which size tuning was tested at more than two contrast values, the low contrast condition was defined as the lowest contrast for which the response was significantly modulated, whereas the high contrast was always defined at $100 \%$ contrast. Because each stimulus was centered on the aggregate receptive field center of all simultaneously recorded units, scatter in the receptive field positions within a single column could result in stimuli that would be off center. To exclude units for which the stimulus was clearly off center, an additional selection criterion that the responses for the sizes $\leq 13.7^{\circ}$ were significantly modulated in response to a high-contrast stimulus was included.

The data were fit with a ratio-of-Gaussians model (Cavanaugh et al., 2002), with a different fit for each contrast or optical stimulation condition by minimizing the mean squared error using the MATLAB function "fminsearch." Successfully fitted units with a mean response for the low contrast or in response to optical stimulation exceeding 0.2 spikes/s were included.

Preferred size. Preferred size was defined as the smallest radius at which the response exceeded $98 \%$ of the unit's maximum response based on the fitted data.

As a control, preferred size was also measured based on the raw data. For this, two different metrics were used: first, the size eliciting the peak mean response and, second, the centroid around the peak response and its adjacent neighbors computed as follows:

$$
S_{\text {pref }}=\frac{\sum_{\substack{x_{a+1} \\ j=x_{a-1}}}^{\sum_{a+1}}\left(j-x_{a}\right) r(j)}{\sum_{j=x_{a-1}}^{x_{a+1}}\left(j-x_{a}\right)}+x_{a}
$$

where $r\left(x_{i}\right)$ are the neuronal mean responses recorded for different stimulus sizes $x_{1} \ldots x_{\mathrm{n}}$, and $x_{\mathrm{a}}$ the stimulus size for which the mean response peaked. If the peak response occurred at the smallest or largest size tested, the size for the peak response was used as the preferred size instead.

SI. The suppression index was defined as the difference between the neuron's maximal response and the response for the largest radius divided by the maximal response. Note that suppression below baseline will result in SI values $>1$.

Cortical depth. After insertion of the electrode, it was verified that the topmost contact was clearly visible and just below the dura. The distance of the contacts of the electrode from the surface of the brain was used as an estimate of cortical depth and the top contact was defined to have a depth of $0 \mu \mathrm{m}$. Superficial recordings were defined as those obtained at depths from 0 to $250 \mu \mathrm{m}$, intermediate as those obtained at depths from 251 to $400 \mu \mathrm{m}$, and deep recordings those obtained at depths $>400 \mu \mathrm{m}$. These depth bands were used for orientation, but they should not be considered to map strictly onto cortical layers.

\section{Results}

We used transgenic mice that expressed channelrhodopsin (ChR2; Boyden et al., 2005) in $\mathrm{PV}^{+}$mice or SOM${ }^{+}$mice. We recorded the extracellular activity of visually responsive SUs and multi-units in V1 of lightly sedated, quiescent mice. Each experiment began by identifying the receptive field centers (see Materials and Methods) of the units and centering the stimulus. Size tuning of each unit was usually estimated in two separate sets of experiments using a circular drifting square-wave grating of varying radius. In the first set of experiments, we measured size tuning at two different contrasts in randomly interleaved trials (240 total units, 103 SUs). In a second set of experiments, we measured it at $100 \%$ contrast while activating $\mathrm{SOM}^{+}$neurons ( 97 total units, 42 SUs) or $\mathrm{PV}^{+}$neurons (253 total units, $104 \mathrm{SUs}$ ) on randomly interleaved trials. All statistical tests were performed for SUs alone and by collapsing across both SUs and multi-units.

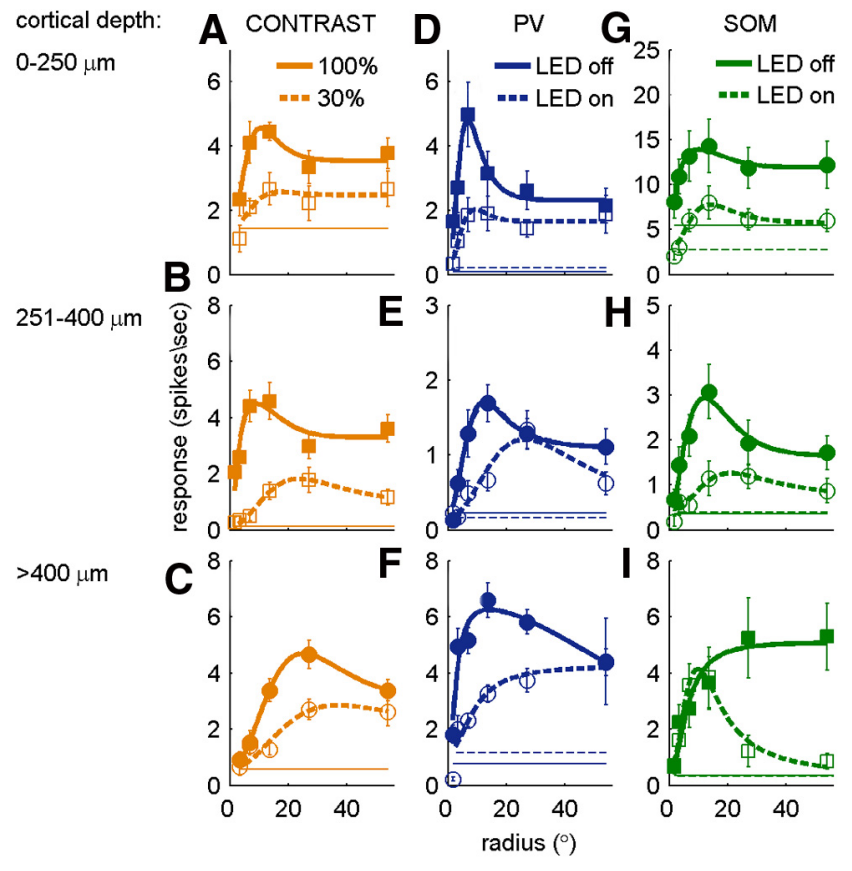

Figure 1. Examples of size tuning across cortical depths for different contrasts or optical stimulation of $\mathrm{SOM}$ or PV neurons. Top, middle, and bottom rows show data recorded at cortical depths from 0 to $250 \mu \mathrm{m}, 251$ to $400 \mu \mathrm{m}$, and $>400 \mu \mathrm{m}$, respectively. A-C, Size-tuning curves obtained for $30 \%$ (open symbols, dashed line) and $100 \%$ contrast (filled symbols, solid line). Note that the maximum response is shifted to a larger radius in response to the lowcontrast grating. Preferred sizes and $\mathrm{SI}$ for the $100 \%$ contrast condition were as follows: $9.5^{\circ}$, $0.22(\boldsymbol{A}) ; 7.8^{\circ}, 0.22(\boldsymbol{B}) ; 22.3^{\circ}, 0.31(\boldsymbol{C})$; and for the $30 \%$ contrast condition were as follows: $14.9^{\circ}, 0(\boldsymbol{A}) ; 21.3^{\circ}, 0.38(\boldsymbol{B}) ; 32.4^{\circ}, 0.05(\boldsymbol{C}) . \boldsymbol{D}-\boldsymbol{F}$, Size-tuning curves recorded in response to $100 \%$ contrast gratings from PV mice for units that were suppressed by activating PV ${ }^{+}$neurons, for $\mathrm{PV}^{+}$neuron activation (LED on, open symbols, dashed lines), and without activation (LED off, filled symbols, solid lines). The effect of activating $\mathrm{PV}^{+}$neurons in these units is similar to lowering contrast (compare left). Preferred sizes and SI for the LED off condition were as follows: $6.4^{\circ}, 0.58(\boldsymbol{D}) ; 11.1^{\circ}, 0.39(\boldsymbol{E}) ; 10.5^{\circ}, 0.38(\boldsymbol{F})$; and for the LED on condition were as follows: $8.4^{\circ}, 0.02(\boldsymbol{D}) ; 23.3^{\circ}, 0.61(\boldsymbol{E}) ; 41.5^{\circ}, 0(\boldsymbol{F}) . \mathbf{G}-\boldsymbol{I}$, Size-tuning curves recorded in response to $100 \%$ contrast gratings from SOM mice for units that were suppressed by activating $50 \mathrm{M}^{+}$ neurons, for $\mathrm{SOM}^{+}$neuron activation (LED on, open symbols, dashed lines), and without activation (LED off, filled symbols, solid lines). Note that for the unit in $I$, activating $\mathrm{SOM}^{+}$neurons results in strong suppression for large radii and shifts the preferred size to a lower radius, very distinct from the effect of lowering contrast. Preferred sizes and SI for the LED off condition were as follows: $7.8^{\circ}, 0.24(\mathbf{G}) ; 10.5^{\circ}, 0.50(\boldsymbol{H}) ; 31.4^{\circ}, 0(\boldsymbol{I})$; and for the LED on condition they were as follows: $12.5^{\circ}, 0.39(\mathbf{G}) ; 18.6^{\circ}, 0.40(\boldsymbol{H}) ; 9.1^{\circ} ; 0.85(\boldsymbol{I})$. Thick lines are fits. Dashed and solid thin horizontal lines depict the baseline response for LED on and off, respectively. Data for contrast, $\mathrm{PV}$, and SOM are shown in orange, blue, and green, respectively. Squares and circles correspond to data from single units and multi units, respectively.

\section{Size tuning varies across cortical depths}

We found that for $100 \%$ contrast stimuli, typical units (Fig. 1, filled symbols) show a maximum response at an intermediate radius but lower firing rates in response to gratings with larger radii, similar to previous results from mouse striate cortex (Van den Bergh et al., 2010; Adesnik et al., 2012). To characterize size tuning, we used two metrics: the preferred size, which corresponds to the minimal radius at which the response reaches $98 \%$ of its maximum, and the SI, which quantifies the degree of suppression by stimuli larger than a neuron's preferred size (see Materials and Methods). We first examined how preferred size and SI changed for different cortical depths for 350 units (146 SUs) recorded both in SOM and PV mice (Fig. 2). Throughout the text, we will refer to depths up to $250 \mu \mathrm{m}$ as superficial, depths between 251 and $400 \mu \mathrm{m}$ as intermediate, and depths $>400 \mu \mathrm{m}$ as deep layers. We found that the median preferred size in deeper 
cortical depth:

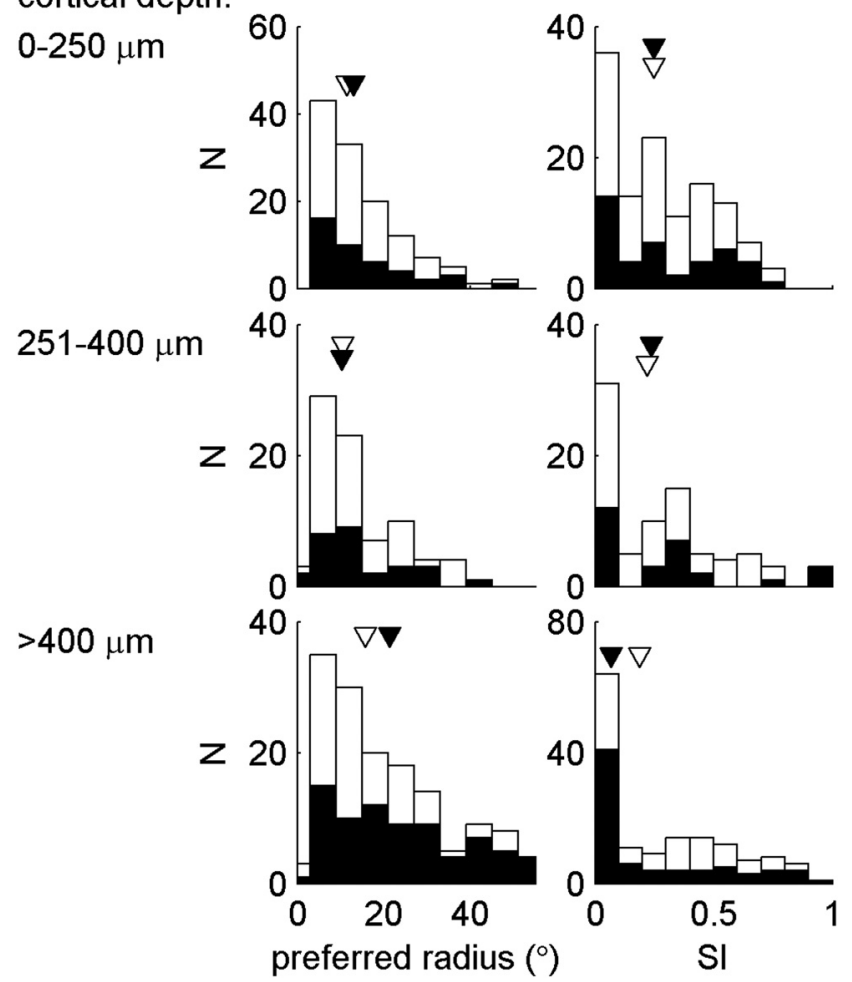

Figure 2. Distribution of preferred size and SI across cortical depths. Filled and open bars depict SUs and all units, respectively. Filled triangles indicate medians for SUs, open triangles median values for all units. Left column shows the distribution of preferred sizes across layers. Note the shift toward larger values for cortical depths $>400 \mu \mathrm{m}$. Right column depicts the distribution of Sls. For cortical depths $>400 \mu \mathrm{m}$, Sls are lower compared with superficial and intermediate layers.

layers was significantly larger than at intermediate $\left(p<10^{-3}\right.$ for all units; $p<0.01$ for SUs only, Wilcoxon rank-sum test) or superficial depths ( $p<0.005$ for all units; $p<0.005$ for SUs only, Wilcoxon rank-sum test). The median preferred size in superficial layers was $11.4^{\circ}\left(n=123\right.$; median preferred size was $13.2^{\circ}$ for SUs only, $n=42$ ) and not significantly different than at intermediate depths $\left(10.5^{\circ}, n=81\right.$ for all units; $10.3^{\circ}, n=28$ for SUs only) and larger in deep layers (median preferred size $15.9^{\circ}, n=$ 146 for all units; median preferred size was $21.4^{\circ}, n=76$ for SUs only). Preferred size has been found to be negatively correlated with SI on a cell-by-cell basis in previous studies (Van den Bergh et al., 2010). It is therefore not surprising that we also observed some differences in SI across depths, with a median SI of 0.19 (median SI $=0.07$ for SUs only) for deeper layers, which was slightly, but not significantly weaker than in superficial (median SI $=0.25, p>0.05$; median SI $=0.25, p>0.05$ for SUs only, Wilcoxon rank-sum test) and intermediate depths (median SI = $0.22, p>0.05$; median SI $=0.24, p>0.05$ for SUs only, Wilcoxon rank-sum test). These variations across cortical depths contrast with the results by Van den Bergh et al. (2010) in urethaneanesthetized mice, in which significant laminar differences were not found in preferred size and SI, but are similar to a recent report (Vaiceliunaite et al., 2013) in awake mice. Although the weak surround suppression in deeper layers is consistent with two recent reports in the mouse (Self et al., 2012; Vaiceliunaite et al., 2013), it contrasts with findings in the macaque (Shushruth et al., 2009). Given the larger receptive field size in deeper layers, it is possible that our largest stimulus, which measured $\sim 3$ times the size of the median preferred size in deeper layers, was too small to elicit stronger surround suppression, possibly explaining the discrepancy with the data from the macaque.

\section{Size tuning for different contrasts}

A striking feature in the macaque monkey (Kapadia et al., 1999; Sceniak et al., 1999) and cat (Sengpiel et al., 1997) striate cortex is that preferred size increases in response to stimuli of lower contrast. We therefore examined the effect of contrast on size tuning. An example is shown in Figure 1B. In response to the lower (30\%) contrast gratings, the radius at which the unit responds maximally was increased (preferred radius is $21.3^{\circ}$ ), whereas the preferred radius at $100 \%$ contrast was $7.8^{\circ}$. This pattern was similar across cortical depths (Fig. 1A-C, Fig. 3, left) and highly significant in the population $\left(p<10^{-16}, n=240\right.$ across all depths; $p<$ $10^{-5}, n=82$ for superficial units; $p<10^{-4}, n=63$ for units at intermediate depths; $p<10^{-7}, n=95$ for deep units, paired $t$ test for all). The results were similar when restricting the analysis to SUs alone $\left(p<10^{-6}, n=103\right.$ across all depths; $p<0.05, n=28$ for superficial SUs; $p<0.07, n=21$ for SUs at intermediate depths; $p<10^{-4}, n=54$ for deep SUs, paired $t$ test for all). Conversely, there was a trend toward weaker SIs at lower contrasts (median SI $=0.16$, median SI $=0.05$, for high and low contrast, respectively, collapsed across depths, $n=240$; for SUs alone median SI $=0.09$ and 0.06 , respectively, $n=103$ ). However while showing a trend ( $p<0.07$ across the population and $p<$ 0.07 for superficial units, paired $t$ tests, Fig. $4 A$, left), it was not significant ( $p>0.1$ for deeper depths or for SUs alone, paired $t$ tests for all, Fig. $4 A$, left), consistent with a previous finding in the macaque (Sceniak et al., 1999; although note that Sceniak et al., 1999 used a different method to quantify surround suppression).

\section{Size tuning when selectively activating $\mathrm{PV}^{+}$neurons}

Next we explored the role that $\mathrm{PV}^{+}$neurons, of which the majority are soma-targeting fast-spiking interneurons, and $\mathrm{SOM}^{+}$ neurons, which mainly consist of dendrite-targeting inhibitory interneurons, play in size tuning and surround suppression by activating these neurons with light. Trials with (LED on) and without (LED off) interneuron activation were randomly interleaved in the same experimental blocks. Only units for which activity was suppressed by activation of $\mathrm{PV}^{+}$or $\mathrm{SOM}^{+}$neurons were analyzed and the light intensity was chosen such that it suppressed the visually driven activity of the recorded neurons to $50-60 \%$. The characteristic effect on size tuning while activating $\mathrm{PV}^{+}$neurons is shown in Fig. $1 D-F$. Activation of $\mathrm{PV}^{+}$neurons increased the preferred size of the recorded units at all cortical depths. This effect is observed in the majority of units and significant in the population at all cortical depths (Fig. $3 A$, middle; $p<$ $0.001, n=79$ for superficial units; $p<0.001, n=61$ for units at intermediate depths; $p<0.001, n=113$ for units in deep layers; $p<10^{-8}, n=253$ across all layers; $p<0.005, n=25$ for superficial SUs; $p<0.01, n=21$ for SUs at intermediate depths; $p<$ $0.05, n=58$ for SUs in deep layers; $p<0.001, n=104$ across all depths, paired $t$ test for all comparisons). For a more detailed analysis of how preferred size changed as a function of cortical depth, we plotted the difference in preferred radius (preferred radius for LED on - preferred radius for LED off) as a function of depth for each unit, where filled and open circles correspond to single units and multi units, respectively (Fig. $3 B$, middle). The running mean of 50 adjacent units (black jagged line, shaded area corresponds to $\pm 1 \mathrm{SE}$ ) is consistently shifted toward values $>0$, indicating that regardless of cortical depth $\mathrm{PV}^{+}$neuron activation increased preferred size, similar to the effect of lowering contrast (compare Fig. 3B, left). Activating $\mathrm{PV}^{+}$neurons also 
A cortical depth:

\section{CONTRAST}

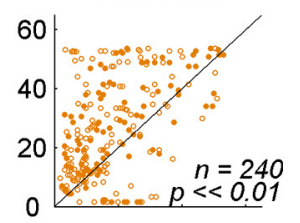

$0-250 \mu \mathrm{m}$
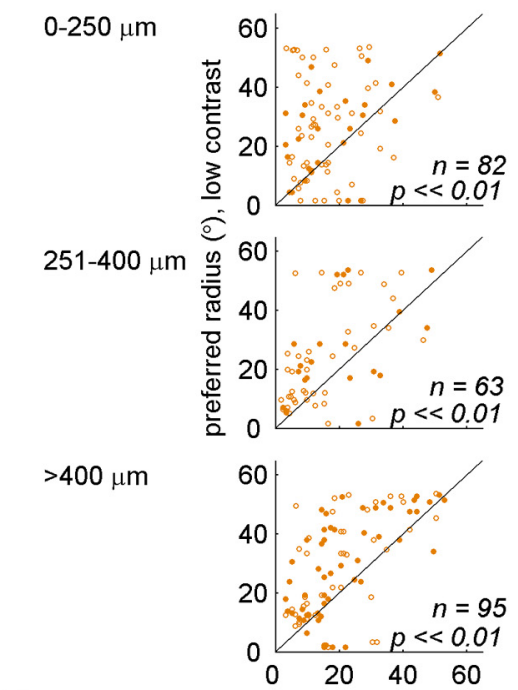

PV
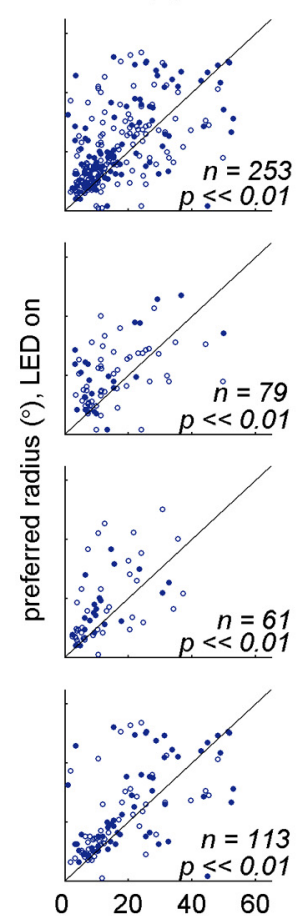

B

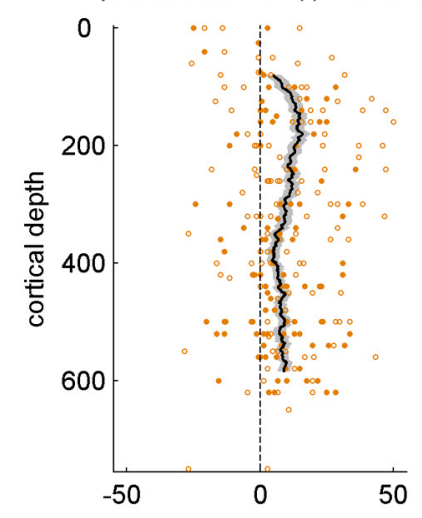

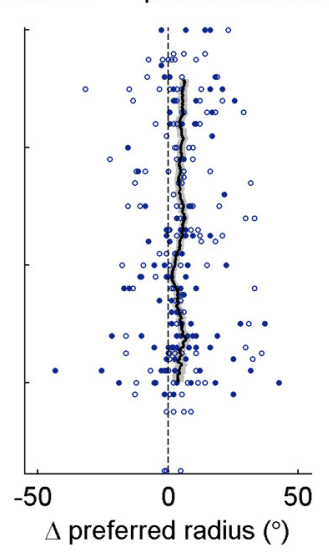

50

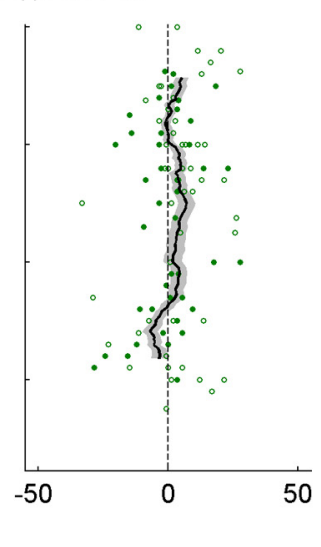

Figure 3. Population data on the effect of contrast and $\mathrm{PV}^{+}$and $\mathrm{SOM}{ }^{+}$activation on preferred size. Filled and open circles are single units and multi-units, respectively. $A$, Top row shows data collapsed across cortical depths. The second, third, and bottom row plot measurements obtained for cortical depths from 0 to $250 \mu \mathrm{m}, 251$ to $400 \mu \mathrm{m}$, and $>400 \mu \mathrm{m}$, respectively. Scatterplots in the first column compare preferred radius for a grating at $100 \%$ contrast ( $x$-axis) and at low contrast ( $y$-axis). At all depths, preferred size is significantly $(p \ll 0.01)$ larger for the lower contrast. Second and third column compare preferred radius for responses without ( $x$-axis) or with ( $y$-axis) activation of $\mathrm{PV}^{+}$(second column) or $\mathrm{SOM}^{+}$(third column) neurons. Middle: At all depths, activating $\mathrm{PV}^{+}$neurons results in significantly $(p<0.05)$ larger preferred radius, similar to lowering contrast. Right: Activating SOM ${ }^{+}$neurons increases preferred radius for superficial neurons $(p<0.05)$, but leads to decreased (not significant) preferred radius for depths $>400 \mu \mathrm{m}$. Therefore, preferred size across all depths does not change significantly. $\boldsymbol{B}$, Difference in preferred size for contrast (left), activating $\mathrm{PV}^{+}$neurons (middle), or activating $\mathrm{SOM}^{+}$neurons (right) is plotted as a function of cortical depth. Dashed vertical line shows $0^{\circ}$ difference. Thin black line represents running mean of 50 units (left and middle) or 20 units (right), shaded gray $\pm 1 \mathrm{SE}$. Left, middle: Across depths the mean is shifted to values $>0$, reflecting the increased preferred radius for low contrasts (left) or for activating PV ${ }^{+}$neurons (middle). Right: For depths $<400 \mu \mathrm{m}$, the mean is slightly shifted to values $>0$, indicating larger preferred radius for activating $\mathrm{SOM}^{+}$neurons, but for depths $>400 \mu \mathrm{m}$, the mean deviates to values $<0$ as activating $\mathrm{SOM}^{+}$neurons reduces preferred radius in deeper cortical layers.

paralleled the effect of lowering contrast on SI: across all depths, there was a trend toward lower SI $(p<0.06$, paired $t$ test), although this trend was not significant for SUs alone or for individual depth levels ( $p>0.1$ for each depth level; $p>0.1$ for the same comparisons for SUs alone, paired $t$ test for all, Fig. $4 A$, middle). The mean difference in SI (SI for LED on - SI for LED off) showed a slight tendency toward values $<0$ (Fig. $4 B$, middle).
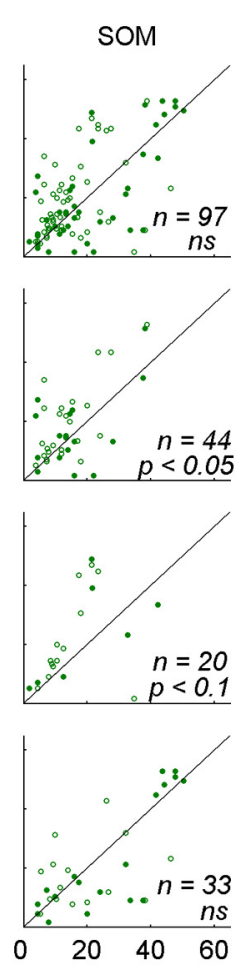

ED off

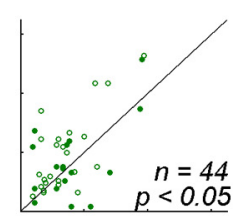

Size tuning when selectively activating $\mathrm{SOM}^{+}$neurons

Conversely, activating $\mathrm{SOM}^{+}$neurons led to a different pattern of effects from that of lowering contrast or activating $\mathrm{PV}^{+}$ neurons, and the characteristics are exemplified in Fig. 1G-I. For cortical depths up to $400 \mu \mathrm{m}$, activation of $\mathrm{SOM}^{+}$resulted in greater preferred size, whereas for the unit recorded at a depth $>400 \mu \mathrm{m}$, activating $\mathrm{SOM}^{+}$neurons led to pronounced suppression and decreased preferred size (Fig. 1I). At the population level, activating $\mathrm{SOM}^{+}$neurons led to increased preferred size in superficial and intermediate layers $(p<0.05, n=44$ for superficial units; $p<0.1, n=20$ for intermediate depths; $p>0.1, n=17$ for superficial SUs; $p>0.1, n=7$ for SUs at intermediate depths, paired $t$ tests), but the decrease in size for units at deeper cortical depths did not reach statistical significance $(p>0.1$, $n=33 ; p>0.1, n=18$ for deep SUs only, paired $t$ test). Because of this mixture of trends across different depths, there was also no significant effect on size tuning when collapsing across depths $(p>0.1$, $n=97$, paired $t$ test). The differential effect on preferred size as a function of depth can more clearly be seen in Fig. 3B, right, which plots the difference in preferred radius (preferred size for LED on preferred size for LED off). The running mean (black line, shaded gray shows \pm 1 SE) is $>0$ for units above $\sim 400 \mu \mathrm{m}$, crosses 0 at $\sim 500 \mu \mathrm{m}$, and is $<0$ for units in deeper layers.

Conversely, we found no significant change of SI in superficial or intermediate layers $(p>0.1$ for all units and SUs alone in both layers, paired $t$ tests), whereas SI was increased in deeper layers $(p<0.02$, $n=33$ for deep layers; $p<0.05, n=18$ for deep SUs; paired $t$ tests; Fig. 4). Note that the majority of superficial units had SIs well below 1 , indicating incomplete suppression such that it should be possible to measure additional suppression by $\mathrm{SOM}^{+}$activation. Our inability to see a significant effect could therefore not be explained by a "ceiling effect." Nonetheless, it is possible that the generally stronger surround suppression in superficial layers limited our ability to detect a significant change in SI for superficial units. In a subset of experiments, we also tested the effect of $\mathrm{SOM}^{+}$neuron activation while presenting low-contrast (median 30\% contrast) stimuli, which causes weaker surround suppression compared with high-contrast stimuli (Fig. 4A, left). Indeed, despite the small sample $(n=9 \mathrm{SUs})$, we found a clear trend toward significantly larger SI for $\mathrm{SOM}^{+}$stimulation in these units $(p<0.09$, paired $t$ test), which is consistent with recent findings (Adesnik et al., 2012). As expected, we also ob- 
served a trend toward smaller preferred sizes in these nine SUs $(p<0.17$, paired $t$ test). The significant increase of SI for $\mathrm{SOM}^{+}$activation was also present when collapsing across all depths $(p<0.01, n=$ 97 for all units across all depths; $p<0.02$, $n=42$ SUs alone across all depths, paired $t$ test). This effect clearly contrasts with our findings for $\mathrm{PV}^{+}$neuron activation and the difference in the effects on SI between $\mathrm{SOM}^{+}$and $\mathrm{PV}^{+}$activation was statistically significant $(p<0.002$, Wilcoxon rank-sum test on the differences in SI for $\mathrm{SOM}^{+}$vs $\mathrm{PV}^{+}$activation). The decrease of SI for $\mathrm{SOM}^{+}$neuron activation with depth is shown in Fig. $4 B$, right, where the running mean of the difference in SI (SI for LED on - SI for LED off) increasingly shifts toward larger values with depth, very different from the effect of activating $\mathrm{PV}^{+}$neurons.

Our measurements of preferred size were derived from ratio of Gaussian model fits to the data (see Materials and Methods). The mean variance explained for these fits was $83.5 \%$, indicating that the fits provided a good description of the data. Nonetheless, to verify that they did not introduce systematic biases affecting our main results, we also compared the changes in preferred size based on the raw data. Note that because of the discrete and fairly coarse sampling of the size-tuning curves, computing preferred sizes based on the peak responses discretized the data and was therefore less sensitive to detecting shifts in preferred size because data points apart from the peak response were ignored. We therefore used a metric that computed the centroid around the peak response and its two adjacent neighbors (see Materials and Methods). This approach decreased the discretization but did not fully abolish the clustering of the data around the sampled values. Nonetheless, this model-free approach yielded the same main results as our results based on fits. For lower contrasts, the preferred sizes were significantly larger $\left(p<10^{-5}\right.$ all units, $p<0.001$ SUs only, paired $t$ tests), similar to $\mathrm{PV}^{+}$activation $(p<$ 0.005 all units, $p<0.05$ SUs only, paired $t$ tests), whereas $\mathrm{SOM}^{+}$activation had no systematic effect across the population $(p>0.1$ all units and SUs only, paired $t$ tests). The results were similar when preferred size was extracted from the raw data based on the peak response while ignoring any other changes in the tuning curve. Preferred sizes increased for lower contrasts and $\mathrm{PV}^{+}$activation (contrast: $p<$ $10^{-4}$ all units, 0.01 SUs only, $\mathrm{PV}^{+}$activation: $p<0.02$ all units, $p<0.09$ SUs only paired $t$ tests), but did not change systematically for $\mathrm{SOM}^{+}$ activation ( $p>0.1$ for all units and SUs alone, paired $t$ tests).

\section{Summarizing the main effects of contrast and activation of either $\mathrm{SOM}^{+}$or $\mathrm{PV}^{+}$neurons}

To facilitate the comparison of the main effects on spatial integration across cortical depths, we superimposed the running mean differences \pm 1 SE in Figure 5, where the data for changing contrast, acti-
CONTRAST
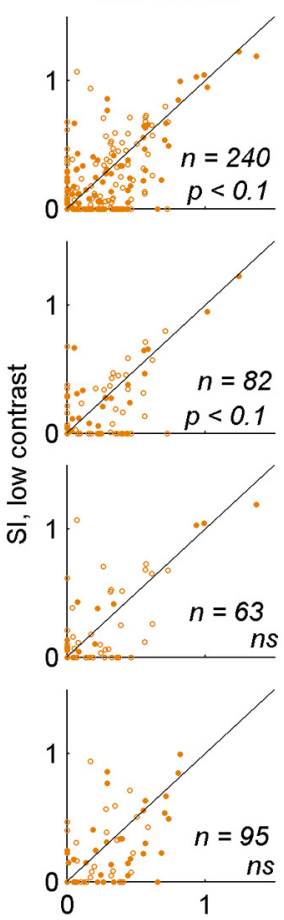

SI, $100 \%$ contrast

B

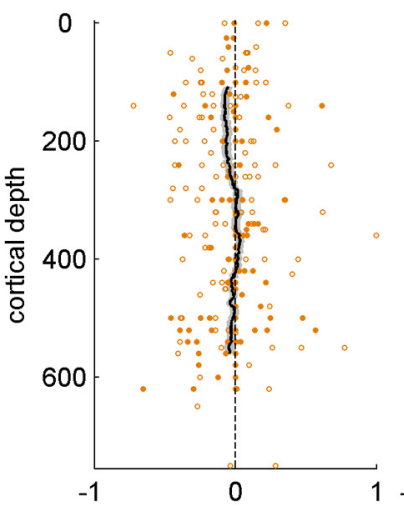

$1-1$
PV
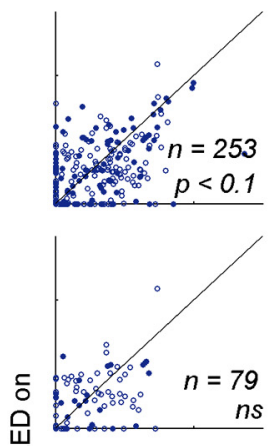

$\bar{\omega}$
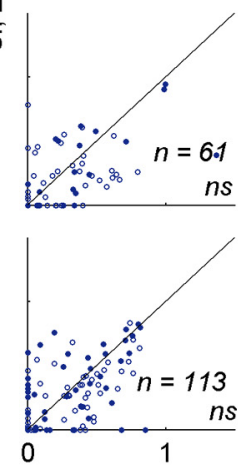

SI, LED off
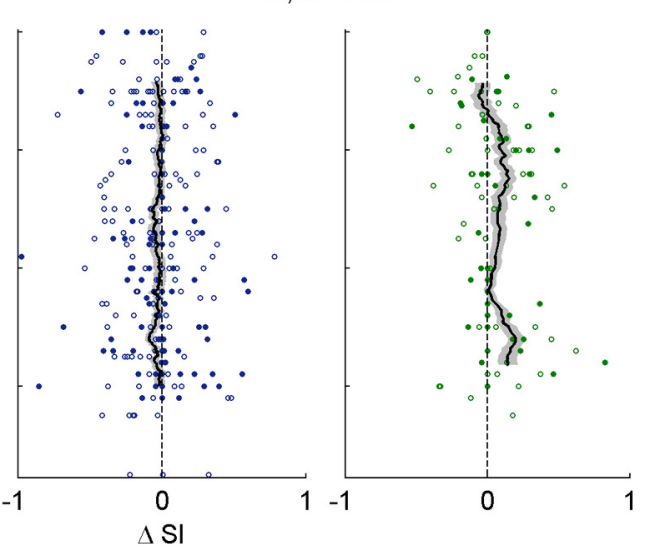

SOM
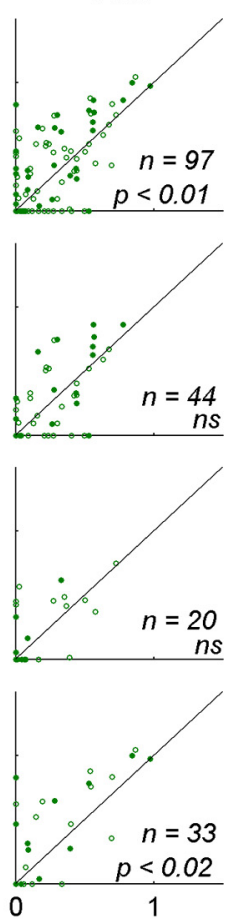$$
0
$$$$
\text { (1) }
$$

Figure 4. Population data on the effect of contrast and $\mathrm{PV}^{+}$and SOM ${ }^{+}$activation on surround suppression (SI). All conventions as in Fig. 3. A, Left and middle: SI does not change significantly in response to gratings of different contrasts (left) or with activation of $\mathrm{PV}^{+}$neurons (middle) across all cortical depths. Right: Activating SOM ${ }^{+}$neurons does not result in a significant change of $\mathrm{Sl}$ at depths $\leq 400 \mu \mathrm{m}$, but for depths $>400 \mu \mathrm{m}$, Sl is significantly larger when SOM ${ }^{+}$neurons are activated $(p<$ neurons (middle), or activating SOM ${ }^{+}$neurons (right) are plotted as a function of cortical depth. Left and middle: Slight but nonsignificant deviations of the mean differences to values $<0$ across depths. Right: For units recorded deeper than $\sim 400 \mu \mathrm{m}$, $\mathrm{SI}$ is significantly larger when activating SOM ${ }^{+}$neurons.

vating $\mathrm{PV}^{+}$neurons, or activating $\mathrm{SOM}^{+}$neurons are shown in orange, blue, and green, respectively. A clear similarity between the effect of contrast and activating $\mathrm{PV}^{+}$is apparent from the nearly complete overlap between the data for changes in SI and the fact that the shift away from 0 was in the same direction for preferred size. In contrast, the data for $\mathrm{SOM}^{+}$neuron activation (green shaded area) significantly deviated from that for contrast variation or $\mathrm{PV}^{+}$neuron activation, particularly in deeper cortex.

To further explore these effects, we also compared the systematic relationship between changes in SI and changes in preferred size for contrast, $\mathrm{SOM}^{+}$, and $\mathrm{PV}^{+}$neuron activation. For all conditions (LED on or off, high and low contrast), we observed a negative correlation between SI and preferred size ( $p \ll 0.01$, Spearman's rank 


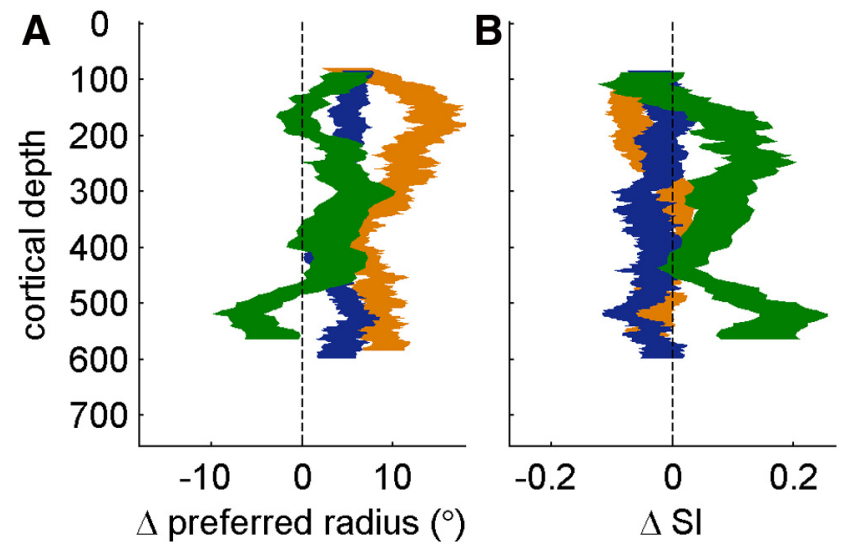

Figure 5. Comparison of the mean effects of contrast and activating $\mathrm{PV}^{+}$and $\mathrm{SOM}^{+}$neurons on spatial integration. Orange, blue, and green lines show data for contrast, $\mathrm{PV}^{+}$activation, and $\mathrm{SOM}^{+}$activation, respectively. $A$, Shaded areas depict the running means $\pm 1 \mathrm{SE}$ from Figure $3 B$, but superimposed to facilitate comparison. Note the similarity between the mean effects for contrast and $\mathrm{PV}^{+}$neuron activation. $\boldsymbol{B}$, Shaded areas compare the running means $\pm 1 \mathrm{SE}$, replotted from Figure $4 B$. Note the deviation of the mean effects of $\mathrm{SOM}^{+}$activation from that for contrast and $\mathrm{PV}^{+}$neuron activation.
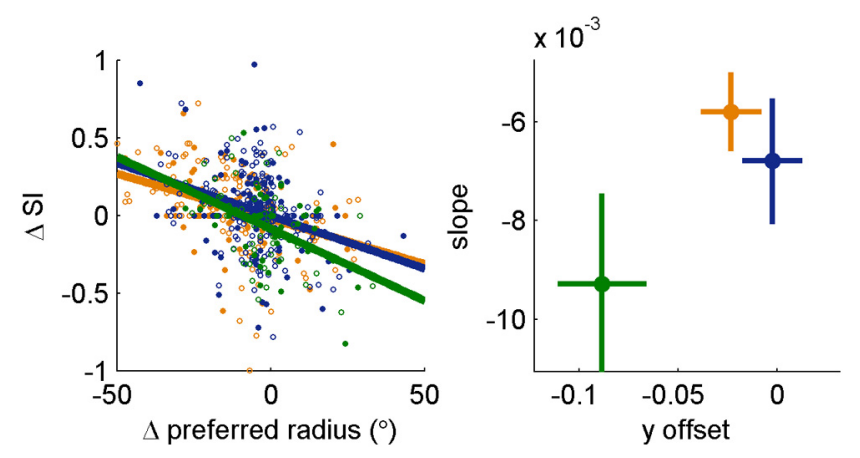

Figure 6. Relationship between changes of preferred radius and changes in SI for varying contrast and activating $\mathrm{PV}^{+}$and $\mathrm{SOM}^{+}$neurons. Orange, blue, and green show data for contrast, $\mathrm{PV}^{+}$activation, and $\mathrm{SOM}^{+}$activation, respectively. Left: For each unit, the change in preferred radius as a function of contrast, $\mathrm{PV}^{+}$activation, or $\mathrm{SOM}^{+}$neuron activation, respectively, is plotted against its change of $\mathrm{SI}$. For each condition, the correlation is highly significant $\left(r=-0.44, p<10^{-12}\right.$ for contrast, $r=-0.28, p<10^{-5}$ for PV ${ }^{+}, r=-0.39, p<10^{-4}$ for $\mathrm{SOM}^{+}$, Spearman's rank correlation). Lines correspond to the type II regression lines. Note the similarity of that for changing contrast and $\mathrm{PV}^{+}$neuron activation. Right: Parameters ( $y$-offset and slope) describing the regression lines are plotted for each condition (error bars depict \pm 1 SE by resampling) to facilitate comparison.

correlation). When comparing the change in SI for change in contrast, $\mathrm{PV}^{+}$, or $\mathrm{SOM}^{+}$activation with the change in preferred size for each unit, we also found a highly significant negative correlation (Fig. 6, left). Interestingly, the regression line (type II regression) describing the changes in SI and size for contrast was very similar to that describing the effect of $\mathrm{PV}^{+}$activation (Fig. 6, left). Conversely, the regression line describing this relationship for $\mathrm{SOM}^{+}$was steeper. This indicates that activation of $\mathrm{SOM}^{+}$led to larger changes in SI than changes in size compared with lowering contrast or $\mathrm{PV}^{+}$ activation, which caused larger changes in size. The differences are clearly captured when plotting the $y$-offset against the regression slope for each condition (Fig. 6, right).

In addition, because SI depends both on the peak response and the response to the largest stimulus, we wondered whether a differential reduction in firing of these for $\mathrm{SOM}^{+}$and $\mathrm{PV}^{+}$neuron activation might account for the different effects on SI. The examples shown in Fig. 1 suggest that $\mathrm{PV}^{+}$neuron activation predominantly reduced the peak response, whereas $\mathrm{SOM}^{+}$neuron activation reduced both the peak response and the response to the largest stimulus. To examine this at the population level, we compared the reduction in peak response (peak response for LED off - peak response for LED on) with the reduction in the response to the largest stimulus (response for LED off - response for $\mathrm{LED}$ on). Indeed, for $\mathrm{PV}^{+}$neuron activation, the reduction in peak response was significantly larger than the reduction to the largest stimulus $\left(p<10^{-8}, n=253\right.$ for all units; $p<10^{-4}, n=$ 104 , SUs only, paired $t$ tests), whereas for $\mathrm{SOM}^{+}$neuron activation, there was no significant difference across the population ( $p>0.1, n=97$ for all units; $p>0.5, n=42$, SUs only, paired $t$ tests).

To ensure that the difference between the effects of $\mathrm{PV}^{+}$and $\mathrm{SOM}^{+}$neuron activation could not be explained by different degrees of suppression of the mean responses between the recording sessions, we compared the reduction of the mean of the visual responses for all units. The median suppression was to $68 \%$ and $62 \%$ for $\mathrm{PV}^{+}$neuron and $\mathrm{SOM}^{+}$neuron stimulation, respectively, not significantly different from each other $(p>0.05$, Wilcoxon rank-sum test; suppression was to $63 \%, 59 \%$, and $63 \%$ for superficial, intermediate, and deep layers for $\mathrm{SOM}^{+}$neuron activation, respectively, and to $67 \%, 68 \%$, and $68 \%$ for superficial, intermediate, and deep layers for $\mathrm{PV}^{+}$neuron activation, respectively; $p>0.05$ for all comparison for all units and for SUs alone, Wilcoxon rank-sum test). This suggests that the discrepancies in the effects between $\mathrm{PV}^{+}$neurons and $\mathrm{SOM}^{+}$neuron activation did not trivially result from different strengths in suppression of the neuronal mean responses; rather, the strikingly different effects of activating these different classes of interneurons suggest a differential role of these neurons on spatial integration.

\section{Discussion}

In this work we have examined how different inhibitory networks in the mouse cortex affect surround suppression, a quantifiable metric with which to study influences that arise from outside of the classical receptive field. To establish a baseline for these comparisons, we characterized for the first time in the mouse the effects of contrast on size tuning and found that the contrast dependence of size tuning resembled that observed in the primate: for lower contrasts, the preferred size increased and there was a trend toward weaker surround suppression. This contrast dependence was similar across cortical depths, although preferred sizes were larger in deeper layers.

We then used optogenetic methods to activate either parvalbumin- or somatostatin-expressing neurons while examining the surround suppression and size tuning of other neurons that were suppressed by this activation. Because the majority of cortical neurons are excitatory, we assume that most of the units we recorded were also excitatory. Although we observed a variety of effects from activation of both neuronal groups, two clearly distinct patterns emerged across the population. Activating $\mathrm{PV}^{+}$ neurons resulted in effects on size tuning and surround suppression that resembled the effects of lowering contrast: it increased preferred size across all cortical depths and resulted in a trend toward weaker surround suppression. This finding is compatible with the notion that activating $\mathrm{PV}^{+}$neurons globally increases feedforward inhibition (Pouille et al., 2009) such that the overall input drive arriving in cortex is decreased, as if one had lowered the contrast of the stimulus. In contrast, activating $\mathrm{SOM}^{+}$neurons had more complex effects on preferred size: it tended to lead to an increase in preferred size at superficial and intermediate 
depths and to a decrease in deeper layers. Moreover, we also found that $\mathrm{SOM}^{+}$neuron activation led to a striking increase in surround suppression, particularly in deeper layers.

The differential effects of activating these two groups could not be explained by different strengths of suppression between these groups of neurons across experiments, but likely reflect their distinct connectivity. $\mathrm{SOM}^{+}$and $\mathrm{PV}^{+}$expression label two nonoverlapping groups of neurons (Xu et al., 2010).

The first group, $\mathrm{SOM}^{+}$neurons, located in layers II-VI, correspond to dendrite targeting inhibitory interneurons, including Martinotti cells (for review, see Markram et al., 2004), and many show widespread axonal arborization in layer I and in the layer in which their somata are located (Wang et al., 2004; Xu et al., 2006; Dumitriu et al., 2007). Based on these anatomical properties and their physiological properties (Ma et al., 2010), it has been suggested that $\mathrm{SOM}^{+}$interneurons are involved in feedback inhibition among cortical columns, layers, and cortical areas. They could therefore be ideal candidates to mediate surround suppression. A recent study found direct support for this proposal in layer II/III of the mouse primary visual cortex (Adesnik et al., 2012). Our data suggest that $\mathrm{SOM}^{+}$neurons mediate surround suppression also at greater cortical depths. At first, this may seem paradoxical given the weak surround suppression we observed for deep layers in the absence of $\mathrm{SOM}^{+}$activation. However, the weak surround suppression for the normal condition may have allowed us to detect the suppressive effect of $\mathrm{SOM}^{+}$neuron activation, as our data for superficial layers suggest (see below). Given the larger receptive field size in deeper layers, it is possible that to detect stronger surround suppression in deeper layers under normal conditions would have required larger stimuli than the largest sizes we tested. Our results suggest that in deeper layers, as previously shown for layer II/III, a circuitry for surround suppression is in place and that $\mathrm{SOM}^{+}$neurons play a role in this circuitry. Although there was also a tendency toward stronger surround suppression for $\mathrm{SOM}^{+}$activation in superficial cortex, these effects were not statistically significant in our study. This contrasts with the findings by Adesnik et al. (2012) and could not be explained by a ceiling effect. However, visual response properties (Niell and Stryker, 2010), including surround suppression (Adesnik et al., 2012; Self et al., 2012; Vaiceliunaite et al., 2013), have been shown to be profoundly influenced by brain state. While we measured surround suppression in lightly sedated mice, Adesnik et al. (2012) used awake, running mice. Moreover, our experiments for low-contrast stimuli suggest that the strong suppression at high contrast in superficial layers limited our ability to detect additional surround suppression driven by $\mathrm{SOM}^{+}$neurons, which may explain the different findings. The results in both studies support the notion that $\mathrm{SOM}^{+}$neurons provide at least in part the local inhibitory influence to drive the cortical component of surround suppression. The question of whether $\mathrm{SOM}^{+}$neurons receive their inputs predominantly from intrinsic connections from neighboring pyramidal neurons, as suggested by Adesnik et al. (2012), or from feedback connections goes beyond our data. However, earlier studies showed that superficial SOM neurons differ from PV neurons and pyramidal neurons by receiving predominantly lateral inputs from within layer II/III and much less feedforward input from layer IV (Xu and Callaway, 2009). The increased SI that we found after $\mathrm{SOM}^{+}$neuron activation may also suggest that $\mathrm{SOM}^{+}$neurons preferentially suppress lateral or feedback connections providing the excitatory drive for large stimuli, perhaps due to their overlapping location with $\mathrm{SOM}^{+}$ terminals in layer 1 .
The second group of neurons studied, $\mathrm{PV}^{+}$neurons, mainly correspond to soma-targeting fast-spiking inhibitory interneurons (for review, see Markram et al., 2004). These have strong connections to neighboring pyramidal neurons (Yoshimura and Callaway, 2005), are involved in cortical feedforward inhibition (Swadlow, 2003; Yoshimura and Callaway, 2005), and generally show broad tuning properties (Niell and Stryker, 2008; Kerlin et al., 2010; Ma et al., 2010; but see also Runyan et al., 2010, who characterized a subset of $\mathrm{PV}^{+}$neurons with sharp tuning). These properties, and the observation that $\mathrm{PV}^{+}$activation and inactivation show little influence on the tuning properties and selectivity of neighboring neurons in visual cortex (Atallah et al., 2012; Wilson et al., 2012, but see also Lee et al., 2012 for contrasting findings, compatible with computational results; Shapley and Xing, 2013), have led to the hypothesis that $\mathrm{PV}^{+}$neurons mediate global gain control (Ma et al., 2010; Atallah et al., 2012; Wilson et al., 2012). Our finding that activating $\mathrm{PV}^{+}$neurons mimics the effect of lowering contrast may thereby at first sight seem counterintuitive, as one would expect that higher contrast is associated with higher $\mathrm{PV}^{+}$neuron activation to maintain the balance of excitation and inhibition in cortex. Moreover, $\mathrm{PV}^{+}$ neuron activation has been suggested to play a role in the generation of rhythmic cortical activity in the gamma range (Cardin et al., 2009) and, in the monkey, increasing stimulus size (Chalk et al., 2010) or stimulus contrast (Ray and Maunsell, 2011) resulted in increased gamma power in the local field potential, suggesting that in both cases, $\mathrm{PV}^{+}$activity may have been enhanced. One might therefore have expected that additional optogenetic activation of $\mathrm{PV}^{+}$neurons would be similar to the effect on size tuning of increasing rather than decreasing contrast. In contrast to that, our results are consistent with the idea that activation of $\mathrm{PV}^{+}$neurons globally increases feedforward inhibition (Pouille et al., 2009), thereby decreasing the overall input drive that arrives in cortex and mimicking a lower contrast stimulus. The cortical circuitry mediating surround suppression, for example, involving $\mathrm{SOM}^{+}$neurons, but possibly involving other circuits as well (Ozeki et al., 2009), therefore processes the visual stimulus as if it were a low-contrast stimulus.

Despite the differences between neurons in mouse V1 and those in cat or primate, such as lower contrast sensitivity and larger receptive fields, it is striking that these neurons mirror basic characteristics of V1 neurons in macaques or cats, such as the contrast dependence of size tuning. Another important difference in the monkey is the distributions of different types of interneurons. Although $\mathrm{SOM}^{+}$neurons are present across layers in macaque V1 (Hendry et al., 1984; Campbell et al., 1987), they are sparse (Hendry et al., 1984) and the proportion of $\mathrm{PV}^{+}$interneurons is higher in the monkey, $\sim 74 \%$ (Van Brederode et al., 1990) compared with $\sim 40 \%$ in the mouse ( $\mathrm{Xu}$ et al., 2010). It is therefore unclear whether the effect of $\mathrm{PV}^{+}$and $\mathrm{SOM}^{+}$neurons on spatial integration is similar in other species such as the monkey.

In the mouse, our data are consistent with a circuit model in which $\mathrm{PV}^{+}$neurons mediate global gain via feedforward inhibition, which for this stimulus paradigm mimics the effect of lowering contrast. Conversely, $\mathrm{SOM}^{+}$neurons mediate surround suppression via feedback inhibition driven either by intrinsic lateral connections (Adesnik et al., 2012) or by feedback from extrastriate cortex, or it may be that $\mathrm{SOM}^{+}$neurons preferentially suppress feedback and lateral inputs providing the excitatory drive for large stimuli. These differential effects are likely mediated by differences between $\mathrm{PV}^{+}$and $\mathrm{SOM}^{+}$neurons in both their outputs (cell bodies vs distal dendrites) and their inputs, 
because superficial $\mathrm{PV}^{+}$neurons receive much stronger feedforward layer IV input than $\mathrm{SOM}^{+}$neurons, which are driven predominantly by lateral inputs from within layer II/III (Xu and Callaway, 2009).

\section{References}

Adesnik H, Bruns W, Taniguchi H, Huang ZJ, Scanziani M (2012) A neural circuit for spatial summation in visual cortex. Nature 490:226-231. CrossRef Medline

Allman J, Miezin F, McGuinness E (1985) Stimulus specific responses from beyond the classical receptive field: neurophysiological mechanisms for local-global comparisons in visual neurons. Annu Rev Neurosci 8:407-430. CrossRef Medline

Angelucci A, Bressloff PC (2006) Contribution of feedforward, lateral and feedback connections to the classical receptive field center and extraclassical receptive field surround of primate V1 neurons. Prog Brain Res 154:93-120. CrossRef Medline

Angelucci A, Levitt JB, Lund JS (2002a) Anatomical origins of the classical receptive field and modulatory surround field of single neurons in macaque visual cortical area V1. Prog Brain Res 136:373-388. CrossRef Medline

Angelucci A, Levitt JB, Walton EJ, Hupe JM, Bullier J, Lund JS (2002b) Circuits for local and global signal integration in primary visual cortex. J Neurosci 22:8633-8646. Medline

Atallah BV, Bruns W, Carandini M, Scanziani M (2012) Parvalbuminexpressing interneurons linearly transform cortical responses to visual stimuli. Neuron 73:159-170. CrossRef Medline

Bair W, Cavanaugh JR, Movshon JA (2003) Time course and time-distance relationships for surround suppression in macaque V1 neurons. J Neurosci 23:7690-7701. Medline

Blakemore C, Tobin EA (1972) Lateral inhibition between orientation detectors in the cat's visual cortex. Exp Brain Res 15:439-440. Medline

Bolz J, Gilbert CD (1986) Generation of end-inhibition in the visual cortex via interlaminar connections. Nature 320:362-365. CrossRef Medline

Bonin V, Mante V, Carandini M (2005) The suppressive field of neurons in lateral geniculate nucleus. J Neurosci 25:10844-10856. CrossRef Medline

Boyden ES, Zhang F, Bamberg E, Nagel G, Deisseroth K (2005) Millisecondtimescale, genetically targeted optical control of neural activity. Nat Neurosci 8:1263-1268. CrossRef Medline

Brainard DH (1997) The Psychophysics Toolbox. Spat Vis 10:433-436. CrossRef Medline

Campbell MJ, Lewis DA, Benoit R, Morrison JH (1987) Regional heterogeneity in the distribution of somatostatin-28- and somatostatin-28(1-12)immunoreactive profiles in monkey neocortex. J Neurosci 7:1133-1144. Medline

Cardin JA, Carlén M, Meletis K, Knoblich U, Zhang F, Deisseroth K, Tsai LH, Moore CI (2009) Driving fast-spiking cells induces gamma rhythm and controls sensory responses. Nature 459:663-667. CrossRef Medline

Cavanaugh JR, Bair W, Movshon JA (2002) Nature and interaction of signals from the receptive field center and surround in macaque V1 neurons. J Neurophysiol 88:2530-2546. CrossRef Medline

Chalk M, Herrero JL, Gieselmann MA, Delicato LS, Gotthardt S, Thiele A (2010) Attention reduces stimulus-driven gamma frequency oscillations and spike field coherence in V1. Neuron 66:114-125. CrossRef Medline

DeAngelis GC, Freeman RD, Ohzawa I (1994) Length and width tuning of neurons in the cat's primary visual cortex. J Neurophysiol 71:347-374. Medline

Dobbins A, Zucker SW, Cynader MS (1987) Endstopped neurons in the visual cortex as a substrate for calculating curvature. Nature 329:438441. CrossRef Medline

Dumitriu D, Cossart R, Huang J, Yuste R (2007 Correlation between axonal morphologies and synaptic input kinetics of interneurons from mouse visual cortex. Cereb Cortex 17:81-91. Medline

Hendry SH, Jones EG, Emson PC (1984) Morphology, distribution, and synaptic relations of somatostatin- and neuropeptide Y-immunoreactive neurons in rat and monkey neocortex. J Neurosci 4:2497-2517. Medline

Hippenmeyer S, Vrieseling E, Sigrist M, Portmann T, Laengle C, Ladle DR, Arber S (2005) A developmental switch in the response of DRG neurons to ETS transcription factor signaling. PLoS Biol 3:e159. CrossRef Medline

Hubel DH, Wiesel TN (1968) Receptive fields and functional architecture of monkey striate cortex. J Physiol 195:215-243. Medline

Ichida JM, Schwabe L, Bressloff PC, Angelucci A (2007) Response facilita- tion from the suppressive receptive field surround of macaque V1 neurons. J Neurophysiol 98:2168-2181. CrossRef Medline

Kapadia MK, Westheimer G, Gilbert CD (1999) Dynamics of spatial summation in primary visual cortex of alert monkeys. Proc Natl Acad Sci U S A 96:12073-12078. CrossRef Medline

Kerlin AM, Andermann ML, Berezovskii VK, Reid RC (2010) Broadly tuned response properties of diverse inhibitory neuron subtypes in mouse visual cortex. Neuron 67:858-871. CrossRef Medline

Kleiner M, Brainard DH, Pelli DG (2007) What's new in Psychtoolbox-3? Perception 36: ECVP Abstract Supplement

Kremers J, Silveira LC, Kilavik BE (2001) Influence of contrast on the responses of marmoset lateral geniculate cells to drifting gratings. J Neurophysiol 85:235-246. Medline

Lamme VA (1995) The neurophysiology of figure-ground segregation in primary visual cortex. J Neurosci 15:1605-1615. Medline

Lee SH, Kwan AC, Zhang S, Phoumthipphavong V, Flannery JG, Masmanidis SC, Taniguchi H, Huang ZJ, Zhang F, Boyden ES, Deisseroth K, Dan Y (2012) Activation of specific interneurons improves V1 feature selectivity and visual perception. Nature 488:379-383. CrossRef Medline

Levitt JB, Lund JS (1997) Contrast dependence of contextual effects in primate visual cortex. Nature 387:73-76. CrossRef Medline

Ma WP, Liu BH, Li YT, Huang ZJ, Zhang LI, Tao HW (2010) Visual representations by cortical somatostatin inhibitory neurons-selective but with weak and delayed responses. J Neurosci 30:14371-14379. CrossRef Medline

Madisen L, Mao T, Koch H, Zhuo JM, Berenyi A, Fujisawa S, Hsu YW, Garcia AJ 3rd, Gu X, Zanella S, Kidney J, Gu H, Mao Y, Hooks BM, Boyden ES, Buzsáki G, Ramirez JM, Jones AR, Svoboda K, Han X, Turner EE, Zeng H (2012) A toolbox of Cre-dependent optogenetic transgenic mice for light-induced activation and silencing. Nat Neurosci 15:793-802. CrossRef Medline

Markram H, Toledo-Rodriguez M, Wang Y, Gupta A, Silberberg G, Wu C (2004) Interneurons of the neocortical inhibitory system. Nat Rev Neurosci 5:793-807. CrossRef Medline

Niell CM, Stryker MP (2008) Highly selective receptive fields in mouse visual cortex. J Neurosci 28:7520-7536. CrossRef Medline

Niell CM, Stryker MP (2010) Modulation of visual responses by behavioral state in mouse visual cortex. Neuron 65:472-479. CrossRef Medline

Ozeki H, Finn IM, Schaffer ES, Miller KD, Ferster D (2009) Inhibitory stabilization of the cortical network underlies visual surround suppression. Neuron 62:578-592. CrossRef Medline

Ozeki H, Sadakane O, Akasaki T, Naito T, Shimegi S, Sato H (2004) Relationship between excitation and inhibition underlying size tuning and contextual response modulation in the cat primary visual cortex. J Neurosci 24:1428-1438. CrossRef Medline

Pelli DG (1997) The VideoToolbox software for visual psychophysics: transforming numbers into movies. Spat Vis 10:437-442. CrossRef Medline

Pennesi ME, Lyubarsky AL, Pugh EN Jr (1998) Extreme responsiveness of the pupil of the dark-adapted mouse to steady retinal illumination. Invest Ophthalmol Vis Sci 39:2148-2156. Medline

Pouille F, Marin-Burgin A, Adesnik H, Atallah BV, Scanziani M (2009) Input normalization by global feedforward inhibition expands cortical dynamic range. Nat Neurosci 12:1577-1585. CrossRef Medline

Ray S, Maunsell JH (2011) Different origins of gamma rhythm and highgamma activity in macaque visual cortex. PLoS Biol 9:e1000610. CrossRef Medline

Runyan CA, Schummers J, Van Wart A, Kuhlman SJ, Wilson NR, Huang ZJ, Sur M (2010) Response features of parvalbumin-expressing interneurons suggest precise roles for subtypes of inhibition in visual cortex. Neuron 67:847-857. CrossRef Medline

Sceniak MP, Chatterjee S, Callaway EM (2006) Visual spatial summation in macaque geniculocortical afferents. J Neurophysiol 96:3474-3484. CrossRef Medline

Sceniak MP, Ringach DL, Hawken MJ, Shapley R (1999) Contrast's effect on spatial summation by macaque V1 neurons. Nat Neurosci 2:733-739. CrossRef Medline

Self MW, Lorteije JA, Heimel JA, Levelt CN, Roelfsema PR (2012) On the mechanisms of orientation-tuned surround suppression in mouse visual cortex. Soc Neurosci Abstr 569.12

Sengpiel F, Sen A, Blakemore C (1997) Characteristics of surround inhibition in cat area 17. Exp Brain Res 116:216-228. CrossRef Medline 
Shapley RM, Xing D (2013) Local circuit inhibition in the cerebral cortex as the source of gain control and untuned suppression. Neural Netw 37:172181. CrossRef Medline

Shushruth S, Ichida JM, Levitt JB, Angelucci A (2009) Comparison of spatial summation properties of neurons in macaque V1 and V2. J Neurophysiol 102:2069-2083. CrossRef Medline

Sillito AM, Versiani V (1977) The contribution of excitatory and inhibitory inputs to the length preference of hypercomplex cells in layers II and III of the cat's striate cortex. J Physiol 273:775-790. Medline

Solomon SG, White AJ, Martin PR (2002) Extraclassical receptive field properties of parvocellular, magnocellular, and koniocellular cells in the primate lateral geniculate nucleus. J Neurosci 22:338-349. Medline

Swadlow HA (2003) Fast-spike interneurons and feedforward inhibition in awake sensory neocortex. Cereb Cortex 13:25-32. CrossRef Medline

Taniguchi H, He M, Wu P, Kim S, Paik R, Sugino K, Kvitsiani D, Kvitsani D, Fu Y, Lu J, Lin Y, Miyoshi G, Shima Y, Fishell G, Nelson SB, Huang ZJ (2011) A resource of Cre driver lines for genetic targeting of GABAergic neurons in cerebral cortex. Neuron 71:995-1013. CrossRef Medline

Vaiceliunaite A, Eriksen S, Franzen F, Katzner S, Busse L (2013) Spatial integration in mouse primary visual cortex. J Neurophysiology, in press.

Van Brederode JF, Mulligan KA, Hendrickson AE (1990) Calcium-binding proteins as markers for subpopulations of GABAergic neurons in monkey striate cortex. J Comp Neurol 298:1-22. CrossRef Medline

Van den Bergh G, Zhang B, Arckens L, Chino YM (2010) Receptive-field properties of V1 and V2 neurons in mice and macaque monkeys. J Comp Neurol 518:2051-2070. CrossRef Medline

Wang Y, Toledo-Rodriguez M, Gupta A, Wu C, Silberberg G, Luo J, Markram H (2004) Anatomical, physiological and molecular properties of Martinotti cells in the somatosensory cortex of the juvenile rat. J Physiol 561: 65-90. CrossRef Medline

Wilson NR, Runyan CA, Wang FL, Sur M (2012) Division and subtraction by distinct cortical inhibitory networks in vivo. Nature $488: 343$ 348. CrossRef Medline

Xu X, Callaway EM (2009) Laminar specificity of functional input to distinct types of inhibitory cortical neurons. J Neurosci 29:70-85. CrossRef Medline

Xu X, Roby KD, Callaway EM (2006) Mouse cortical inhibitory neuron type that coexpresses somatostatin and calretinin. J Comp Neurol 499:144-160. CrossRef Medline

Xu X, Roby KD, Callaway EM (2010) Immunochemical characterization of inhibitory mouse cortical neurons: three chemically distinct classes of inhibitory cells. J Comp Neurol 518:389-404. CrossRef Medline

Yoshimura Y, Callaway EM (2005) Fine-scale specificity of cortical networks depends on inhibitory cell type and connectivity. Nat Neurosci 8:1552-1559. CrossRef Medline

Zipser K, Lamme VA, Schiller PH (1996) Contextual modulation in primary visual cortex. J Neurosci 16:7376-7389. Medline 